\title{
PONER EN PALABRAS LO TRAUMÁTICO: MUJERES SOBREVIVIENTES DE ABUSO SEXUAL
}

\author{
Irene Fridman
}

\section{Introducción}

El trabajo realizado como supervisora clínica del "Programa de asistencia a la víctima de violencia sexual” (del Gobierno de la Ciudad Autónoma de Buenos Aires) y en especial de las víctimas de incesto, me ha permitido pensar y elaborar teóricamente acerca de las dificultades específicas de este tipo de abordaje clínico, de lo singular del modo de padecimiento de las sobrevivientes de incesto, como así también profundizar acerca de las secuelas secundarias ${ }^{1}$ generadas en muchos casos por abordajes clínicos en los cuales el relato de abuso sexual ha sido interpretado solamente desde el espacio psíquico deseante con la consecuente desmentida de lo que acontece en una mujer cuando es víctima de violencia sexual.

Ya en otros trabajos (Fridman 2003, 2004, 2005) propuse la interrogación crítica de textos que sometidos al discurso del Amo producían efectos iatrogénicos en las mujeres que denunciaban haber sido víctimas de este tipo específico de violencia, y en esos textos aclaré, acerca del deber ético que tenemos los terapeutas que abordamos este tipo de trabajo, la necesidad de visibilizar los atravesamientos teóricos al servicio de la práctica patriarcal.

Muchos puntos de la teoría psicoanalítica están en pleno proceso de revisión y cuestionamiento, con el fin de develar las estrategias de silenciamiento o de patologización con que son connotadas las experiencias femeninas, estrategias que tuvieron como fin último mantener de alguna manera el status subordinado del colectivo

\footnotetext{
${ }^{1}$ Denomino efectos secundarios a la práctica clínica que genera iatrogénica diferenciándola de los efectos primarios que tendrían que ver con las secuelas directas del incesto.
} 
femenino. Es por esto que mi intención es poder dar cuenta de algunos lineamientos teóricos con los que vengo trabajando en el abordaje y compresión de las secuelas traumáticas de mujeres que han sido víctimas de violencia sexual en especial de incesto.

\section{Psicoanálisis y teorías de género. Un diálogo difícil}

Una definición marco de Ética plantea que esta rama de la filosofía se aboca al estudio y análisis del “conjunto de normas y creencias (reales o ideales) sobre las conductas humanas individuales o sociales que de alguna manera determinan lo que está bien y lo que está mal” (Luna, 1995).

Actualmente la preocupación por las cuestiones éticas en diferentes disciplinas está íntimamente relacionada con la interrogación acerca de la noción de una verdad universal y para todos. El cuestionamiento posmoderno acerca de quién es el sujeto de la historia es seguido por la interrogación acerca de quién es el sujeto de la moral, y de la moral para quién.

Dentro de este marco el psicoanálisis y sus prácticas también son interrogados como no podía ser de otra manera, ya que hasta ahora el desarrollo psicoanalítico es la construcción teórica más importante acerca de cómo los sujetos en nuestra cultura devienen en varones y mujeres con características diferenciales descriptivas y prescriptivas para cada género.

El psicoanálisis, un desarrollo teórico que se edifica todavía en pleno auge de la modernidad, pero que cabalga en los comienzos de la posmodernidad, trae en su seno, a través de la formulación de la noción de Inconsciente, el cuestionamiento más importante hecho hasta ese momento a la noción de sujeto unificado, y de lo que ello implica para el paradigma de la modernidad de un sujeto racional y consciente.

La construcción del cuerpo teórico psicoanalítico se realiza en un momento fecundo de crisis de la historia, y no puede ser ajeno a nosotros que Freud construye su teoría haciendo luz sobre el padecimiento subjetivo que les plantea a las mujeres el advenimiento de una forma de feminidad que marca y delimita el orden cultural. 
Lucien Israel en su libro El goce de la histeria (1979) hace referencia a lo que él denomina “el elogio de la histeria”, y menciona “que la primera neurosis escuchada fue la de la histeria, esto le permitió a quien escuchaba introducir o crear el discurso psicoanalítico (...). El psicoanalista es siempre precedido aún hoy por una histeria”. Siguiendo esta línea de pensamiento, ¿qué sucede si trasvolamos la denominación histérica por mujer?, suceso que ha acontecido a lo largo de la historia ${ }^{2}$ ¿ ¿No será que lo que empieza a aparecer aquí es la voz de las mujeres cuestionando su lugar como "Lo otro" de la cultura, poniendo en palabras por primera vez el malestar femenino que es consecuencia de su lugar de subordinación, palabras que son recogidas por el creador del psicoanálisis?

Muchas de las teorizaciones acerca de la feminidad en el corpus freudiano son cuestionables; Emilce Dio Bleichmar $(1991,1998)$ menciona que este aspecto de la teoría es el talón de Aquiles de la misma.

Los aportes de las primeras psicoanalistas críticas hacia las concepciones de la feminidad enunciadas por Freud, y después los cuestionamientos que han venido realizando las feministas, han conmovido y lo siguen haciendo el edificio psicoanalítico como nunca antes había ocurrido y bien venido sea.

La toma de conciencia de los efectos subjetivos que conlleva estar ubicados en el estatuto del "lo otro" de la historia, de la no pertenencia a lo que se consideraba el sujeto universal de la historia, el varón blanco heterosexual de los países centrales, permitió habilitar otros discursos más allá del oficial androcentrico que es sospechoso de parcialidad.

La inclusión dentro de los análisis teóricos de los efectos subjetivos de las relaciones de poder entre los actores en juego permitió ampliar e interrogar la veracidad de ciertas definiciones atributivas y valorativas a cada género, incluyendo la noción de alteridad no jerárquica.

\footnotetext{
${ }^{2}$ Este tipo de traspolación ha sido común a lo largo de la historia. Ver en este sentido el análisis que hace Ana Fernández en La mujer de la ilusión.
} 
A partir de los cuestionamientos feministas acerca de las implicancias en la subjetivad de varones y mujeres de las relaciones jerárquicas de dominación y subordinación que propone el orden patriarcal, se intenta modificar un cierto tipo de arreglo cultural que atribuye características diferenciales a cada género, y que tienen el fin de preservar el arreglo sexo-género de este orden cultural. En este sentido las feministas sexualizan el discurso en crisis, incluyendo y deconstruyendo lo que implica la variable jerárquica en la construcción de la subjetividad (Rosi Braidotti, 2000). Muchos puntos de la teoría psicoanalítica están en pleno proceso de revisión y cuestionamiento con el fin de develar las estrategias de silenciamiento o de patologización con que son connotadas las experiencias femeninas, como forma de mantener el status subordinado del colectivo femenino. Junto con esto también se han silenciado o patologizado las experiencias de los varones que no corresponden a lo esperado en el imaginario acerca de la masculinidad hegemónica.

Es por esto necesario la interrogación crítica de un discurso científico que todavía tiene dificultad de incorporar la voz de aquéllos a los que se denominó lo Otro de la cultura, patologizando o efectuando operaciones de desmentida acerca de su experiencia. O sea, los discursos que no incorporen en su teorizaciones los efectos de las relaciones de poder en el análisis de la diferencia sexual. El posicionamiento personal que mueve este trabajo tiene que ver con interrogar una práctica psicoanalítica para que se pueda escuchar desde otro lugar lo que el psicoanálisis ha dogmatizado y desde ahí poderse plantear abordajes que tengan realmente en cuenta la singularidad de las mujeres y sus prácticas reales, no lo que el colectivo masculino a imaginarizado como "la mujer”, teniendo en cuenta los efectos del poder simbólico como estructurante, y que éste en muchos casos ha estado al servicio de desmentir las consecuencias subjetivas de las prácticas de poder, nominando estas experiencia desde la ubicación de la patología o adscribiéndola solamente al espacio psíquico edípico deseante ${ }^{3}$.

\footnotetext{
${ }^{3}$ Es común todavía escuchar relatos de pacientes que vuelven a analizarse acerca de cómo en tratamientos anteriores cada vez que narraban acerca de sus experiencias incestuosas, los
} 
Los nuevos paradigmas que surgen de la mano de los cuestionamientos de las teóricas de las relaciones de género tienen que tener influencia en los textos clásicos freudianos ya que "para que una disciplina siga viva, no debemos mantenerla intacta sino justamente renovar sus fundamentos, ya que toda teoría que no admite lo novedoso corre el riesgo de morirse” (Hornstein, 1994). Quizás este sea el lugar de las/los psicoanalistas con perspectiva de género.

Son por todos conocidas las tormentosas relaciones entre el psicoanálisis y las teorías de género. Esta pelea a mi entender esteriliza lo que podría ser un movimiento fecundo de revisión de una teoría que repite sin efectuar un análisis crítico, las relaciones de subordinación que se han dado históricamente entre varones y mujeres.

La dificultad que presentan algunos teóricos del psicoanálisis en la inclusión de los aportes de las teorías de género podría estar evidenciando la tensión entre las representaciones acerca de lo femenino desde el discurso patriarcal y las vivencias de las mujeres que gracias a los aportes feministas se empiezan a escuchar.

\section{Deconstruyendo la feminidad freudiana}

Una frase que marcó los destinos del psicoanálisis es la que enuncia Freud en sus trabajos sobre sexualidad femenina y sobre la feminidad, cuando postula "la anatomía es destino".

La inclusión de los aportes feministas nos obliga a deconstruir que quiere decir “anatomía” y “destino”. Gracias a los trabajos de Michael Foucault sabemos que la noción de corporalidad alude a un cuerpo marcado y atravesado por la cultura, muy lejano de la concepción de naturaleza con que se ha identificado históricamente el cuerpo femenino.

Desde esta noción, la corporalidad es vista como el lugar donde se juega la subjetividad sexuada, y con esto estamos diciendo que el cuerpo, es el sustrato material

terapeutas les interpretaban que estos sucesos tenían que ver con fantasías ligadas a sus deseos edípicos. 
atravesado por las relaciones de poder en clave jerárquica, pantalla proyectiva y representativa del orden cultural.

La concepción de un cuerpo de mujer atravesado por el significado de ser objeto de deseo, y no sujeto, es un proceso histórico que ha determinado efectos de verdad y producción de conocimientos, es por esto que resignificando los postulados freudianos podemos hacernos eco de la relectura que realiza Rosi Braidotti cuando dice: “la historia antes que la anatomía es destino”.

En relación a lo anterior creo importante poder analizar lo que significópara las teorizaciones posteriores el cambio de la primera tópica a la segunda tópica en el marco de las conceptualizaciones psicoanalíticas. Sigmund Freud modificó su primer postulado teórico acerca del suceso traumático sexual en la etiología de las neurosis femeninas, para pasar a elaborar el concepto de realidad psíquica y deseo reprimido en relación a la conflictiva edípica. No podemos negar la importancia del descubrimiento freudiano acerca de la realidad psíquica y del inconsciente, pero también es necesario poder apreciar el efecto teórico y político que significó esta modificación para las mujeres y para la práctica psicoanalítica cuando se negó la habitual práctica de violencia en contra de las mujeres y su efecto devastador a nivel psíquico.

Creo firmemente que cuando Freud modifica su explicación de la etiopatogenia de las neurosis no lo realiza al menos concientemente como un intento espurio de que su teoría sea aceptada por el status científico dominante en la época, como plantea Masson en su libro El asalto a la verdad (1985); más bien me posiciono en que este proceso se debió a dificultades epistemológicas debido a los paradigmas imperantes en su época. Pero no tengo ninguna duda que ya es hora que los teóricos actuales podamos realizar esta revisión en beneficio de las/los víctimas de abuso teniendo en cuenta que históricamente los efectos subjetivos de la violencia sobre los colectivos subordinados han sido silenciados y que la pelea histórica entre el psicoanálisis y las teorías de género solo puede estar al servicio de cristalizar relaciones de dominación entre varones y mujeres. En cambio la interlocución enriquecedora de estas dos teorías permitiría un 
dialogo fecundo aceptando la alteridad no jerárquica con todo lo que esto implica en el ámbito político y de la teoría.

Ser víctima de violencia sexual con toda la característica diferencial que esto trae evidencia el "padecimiento de ser mujer”, término que devela que "por el solo hecho de ser mujeres, tenemos una representación de ser sujetos pasibles de violencia” (Fridman, 2005). Es en este sentido que nos adscribimos a la reelaboración política que realiza Rosi Braidotti (2000) de la famosa frase de Freud “anatomía es destino” en "la historia de la anatomía es destino”, puntualizando la íntima relación entre la representación de las mujeres y la violencia padecida.

La violencia contra las mujeres genera modos de constituirse como sujetos en el espacio público y determina pautas conscientes e inconscientes, estrategias de posicionamiento social y también mecanismos de defensa que se ponen permanentemente en juego y que marcan un “alerta femenino” (que está ausente en la subjetividad masculina que padece otro tipo de alerta en relación a los fantasmas temidos por los modos de masculinización social) (Fridman 2005), y que solo puede ser equiparado a las vivencias de vulnerabilidad social que padecen los colectivos marginados. En este sentido no dudo en afirmar que debemos incluir la violencia sexual como forma de control social y de fragilización subjetiva de un colectivo.

Cuando un sujeto subordinado se presenta a cuestionar una práctica preestablecida y denuncia el efecto de violencia que esta práctica conlleva, muchas veces por su solo status de marginado, no es validado en su denuncia. Albert Memmi en su texto The colonizer and the colonized (1997) teoriza acerca de las formas en que se posiciona a la personas que desde un lugar de sometimiento e, insertas en relaciones de asimetría, intentan tener un accionar de cuestionamiento acerca de una práctica preestablecida, reflejando en este posicionamiento un modelo similar al que padecen los colonizados frente al colonizador: la ubicación del otro en el colonizado permite describirlo como un No, un vacío, o una falta; hay un intento por tratar de que el colonizado exista solamente en función de las necesidades del colonizador. Volvamos a 
relacionar esto con las muchas veces no escuchada prédica de las mujeres que denunciaban ejercicio de violencia sobre sí.

Las voces de las mujeres abusadas fueron por años sometidas a un ejercicio de silenciamiento hasta que de la mano de las mujeres que pudieron poner palabra a esta práctica surgieron los cuerpos-palabras fragmentados y dañados

Un hecho similar a lo que ocurrió con los desaparecidos de la dictadura argentina, silencios que producían efectos subjetivos y simbólicos a pesar de la prohibición de los grupos dominantes. No me parece casual que las que dieron visibilidad y cuerpo a los desaparecidos hayan sido otro grupo de mujeres, las Madres de Plaza de Mayo, que reclamaban por la aparición de éstos, otorgándoles un lugar en el silencio oficial. Y creo adecuado comparar las prácticas del terrorismo del pater Estado con las prácticas abusivas de ciertos paterfamilias que ejercen un poder similar al que ejerció la dictadura en sus ciudadanos, el poder de ejercicio de lo siniestro

Es por esto que una de las preocupaciones acerca de la ética en la práctica psicoanalítica me lleva a revisar los efectos subjetivos que ha tenido en las pacientes mujeres víctimas de abuso cierto tipo de abordaje psicoanalítico que solamente ha trabajado la situación de abuso sexual desde la óptica del deseo inconsciente, aumentando las vivencias de culpa y no dando lugar a la elaboración de los sentimientos que despierta ser sujeto pasivo de violencia.

\section{Incesto: la dificultad de testimoniar}

¡Que el día no me tome con sus resoluciones! Que la luz en mi frente me mostrará grabada la historia de mi dulce castidad derrotada, (...) y hasta el torpe iletrado, incapaz de leer lo escrito en esos libros para su aprendizaje, descubrirá mi sucia violación en mis ojos.

William Shakespeare, La violación de Lucrecia 
¿Podremos nosotros los psicoanalistas develar y ayudar a elaborar estas vivencias que no tan poéticamente nos relatan las pacientes que han sido abusadas por su padre o por algún familiar cuando eran niñas?

Muchas veces en nuestra consulta escuchamos el relato de pacientes que nos describen una vivencia similar, de estar marcadas para siempre, de haber sido objeto de violencia sexual por parte de algún miembro significativo de su familia. No siempre aparece el relato en forma manifiesta, pero sí lo inferimos, por el sufrimiento que presentan, por los síntomas, o por cierto tipo de modalidad contratransferencial que nos devela la presencia de algún tipo de trauma sexual en clave de abuso incestuoso.

Uno de los primeros interrogantes que aparecen cuando se trabaja en este tipo de abordaje tiene que ver con la dificultad de testimoniar por parte de las mujeres que han sido víctimas de práctica incestuosa como así también de los efectos que ese testimonio tiene sobre los que lo escuchan.

¿Por qué utilizar la palabra testimoniar? A partir de los relatos de los sobrevivientes de campos de concentración nazi, y del magistral testimonio que nos ha dado Primo Levi en sus libros Si esto es un hombre y Los hundidos y los salvados, la acepción de testimonio ha cobrado mucho interés en la línea de análisis acerca de la veracidad de estos relatos, de la posibilidad de escuchar el horror y de los efectos que los testimonios han tenido sobre los que han presenciado estas narraciones. En este sentido todos los análisis que se han realizado en función de lo que se denomina “después de Auschwitz" me han permitido pensar acerca de otros testimonios, que históricamente han sido desmentidos, cuestionados, o desvirtuados en virtud de operaciones más políticas que analíticas, comprobando que muchas de las descripciones que escuchamos de las vivencias de los sobrevivientes de los campos de concentración se asimilaban a lo que ocurría con las víctimas de violencia sexual (considero que en todo relato de personas sometidas a violencia social aparecen este tipo de descripciones)

¿Por qué pensar el Holocausto para pensar estos temas? Porque me posibilita pensar en otras violencias sobre colectivos subordinados: el Holocausto es la muestra horrorosamente dimensionada de otros actos siniestros de la cultura. Si en algún lugar lo 
que pasó en Auschwitz es del orden de lo indecible, ligado a lo siniestro por el imperativo de la destrucción del otro, por qué no poder pensar en los otros indecibles, los que ocurren dentro de una familia y que ejemplifican el uso demencial y despótico del poder al servicio de la aniquilación de la subjetividad de la niña, lo otro en este caso.

Trabajar sobre los relatos de los sobrevivientes al Holocausto y también a lo que aconteció con las víctimas de terrorismo de Estado en Argentina me permitió pensar y comprender mejor las vivencias de las mujeres que han estado sometidas a prácticas incestuosas por algún adulto significativo de la familia, y de esta comprensión poder estrategizar mejores abordajes clínicos.

Si bien la noción de genocidio se aplica a la desaparición de un grupo humano que tiene características similares por etnia, no puedo dejar de relacionar esta acepción con la histórica violencia que se viene perpetrando con las mujeres, muchas de las cuales suceden al interior de una familia. Ya un sociólogo norteamericano, Teodore Winkler, describió en su texto Mujeres en un mundo inseguro lo que él denominó “el genocidio escondido”, en el cual devela en cifras escalofriantes los millones de mujeres que son víctimas de violencia con daño físico permanente o muerte. Es por esto que la acepción de genocidio vuelve a hacer pensar en la necesidad de recurrir al análisis de estos sucesos históricos para entender qué acontece con el colectivo femenino y pensar que esta violencia está más allá de la pertenencia a uno u otro nivel sociocultural y/o étnico, del primer mundo o del tercer mundo. La idea del pacto interclase para la violencia contra la mujer vuelve a tomar relevancia ${ }^{4}$.

\section{Sobreviviendo al incesto}

El trabajo clínico con mujeres que han sobrevivido a la violencia sexual nos posiciona a nosotros como terapeutas en la senda de la reescritura como modo de

\footnotetext{
${ }^{4}$ Se denomina pacto interclase al acuerdo social no explícito del patriarcado de llevar a cabo la subordinación de las mujeres a los varones mas allá de su pertenencia a distintos sectores sociales, étnicos o culturales.
} 
elaboración de una narrativa profundamente traumática. Según Dominick La Capra (2005) el testigo en segundo grado es el que va a hablar de acuerdo al testimonio escuchado (en este sentido se denomina al historiador "testigo en segundo grado"), abriendo una interrogación acerca de si los psicoanalistas cuando teorizamos en función de lo relatado por los pacientes de alguna manera no nos convertimos en testigos de segundo grado.

El incesto se inscribe dentro de lo que consideraríamos una experiencia catastrófica con características diferenciales comparadas con cualquier otro suceso traumático vivido.

Si el trauma es concebido como la impasse en una lógica que trabajosamente pone en funcionamiento los esquemas previos, y el acontecimiento como la invención de unos esquemas otros frente a esa impasse, la catástrofe sería algo así como el retorno al no ser. Es posible pensarla como una dinámica que produce desmantelamiento sin armar otra lógica distinta pero equivalente en su función articuladora. De esta manera, lo decisivo de la causa que desmantela es que no se reitera, esa permanencia le hace obstáculo a la recomposición traumática y a la fundación acontecial. Por eso mismo, no hay ni esquemas previos ni esquemas nuevos capaces de iniciar o reiniciar el juego. Hay sustracción, mutilación, devastación. (Leucowics, 2002)

En la catástrofe psíquica que produce la irrupción del incesto en la vida de la niña (Fridman, 2005) lo acontencial no tiene lugar, sino que lo que queda desvastado no puede ser reelaborado, dejando secuelas en forma de traumas muchas veces inelaborables. Es en este sentido que se hace necesario en un primer momento poder trabajar con el proceso de la memoria, o sea, el rescate de lo que quedó fuera del relato tanto sea por escisión o por desmentida.

Paul Ricoeur (2004) postula que la memoria es principalmente memoria en el cuerpo y que la misma "se constituye como el aquí respecto del cual todos los otros lugares están allá”, es por esto que dice: “Es más importante para nuestro propósito considerar el lado de la memoria colectiva, para encontrar en su nivel el equivalente de las situaciones patológicas en las que tiene que tratar el psicoanálisis”. 
Es por esto que no podemos ser ajenos a que el cuerpo de las mujeres abusadas es el reservorio más fino de la memoria del suceso, solamente hay que saber leerlo y “escuchar su testimonio” y este es el lugar de nosotros, los psicoanalistas entre otros.

El trabajo de la memoria abre un sendero a la elaboración del relato de la persona que se erige en testigo. Denominando testigo a aquellos que relatan lo vivenciado y acontecido y que en sucesos históricos catastróficos se erigen en la voz de los que no puede hablar los testigos integrales que según Levi son los muertos o los desaparecidos, o sea el que padeció todo hasta sus ultimas consecuencias ${ }^{5}$ (para diferenciarse de la persona que atestigua en la contienda entre dos).

Dice Paul Ricoeur (2004):

El testigo pide ser creído, por lo tanto solo es completo su acto cuando es aceptado su testimonio (...) Sobre el fondo de esta presunta confianza se destaca trágicamente "la soledad de los testigos históricos" cuya experiencia extraordinaria echa en falta la capacidad de comprensión media ordinaria. Hay testigos que no encuentran nunca la audiencia capaz de escucharlos y oírlos ${ }^{6}$.

En esta línea de análisis, el trabajo de la memoria en los casos de mujeres abusadas permite poder dar cuenta de los sucesos traumáticos y habilitaría la posibilidad de elaboración del mismo, lo que una autora denominó “rescate de las voces exiliadas”, proceso que implicaría rescatar de la disociación y ayudar a elaborar lo que se ha escindido no solamente por efecto traumático sino también por efecto de la desmentida (Roger, 2000), abriendo el trabajo terapéutico no solamente hacia la persona que “da su testimonio" sino permitiendo romper el histórico silencio que ha impedido un abordaje individual y social de esta conflictiva.

Lucila Edelman y Diana Kordon (2002), refiriéndose a las víctimas del terrorismo de Estado en Argentina postulan que el efecto de retraumatización tiene que ver con el hecho de que

\footnotetext{
${ }^{5}$ Primo Levi denomina musulmán al testigo integral ese sobre el cual la desubjetivaciòn ha sido tan efectiva que no puede relatar por su desaparición.

${ }^{6}$ La cursiva es mía.
} 
el cuerpo agredido y amenazado, la familia fracturada, las instituciones, el cuerpo social y aún el Estado pierden para el sujeto sus funciones apuntaladoras, situación sumada al silencio tanto por parte de la persona por la prohibición de hablar como por parte del entramado social por desmentida, [lo que] posibilita la inelaborabilidad del trauma.

No puede dejar de llamar la atención la similitud de este proceso con lo que ha ocurrido con las sobrevivientes de incesto, por lo que el trabajo con la memoria y la recuperación de lo que ha estado escindido no solamente apunta a la posibilidad de elaboración del trauma sino también a poder dar cuenta desde lo social de apoyaturas más adecuadas para el trabajo de las mujeres que han pasado por esta situación traumática.

Las mujeres abusadas aprenden a desautorizar al yo (Stern, 1991), los recuerdos que son disociados, muchas veces no es que no aparezcan en la conciencia sino que surgen escindidos de afectividad y por lo tanto vaciados de contenidos.

Lo que se ha desmentido en estas narraciones no ha sido casual, sino que ha tenido que ver con la desautorización que históricamente han tenido algunos colectivos de denunciar ser víctimas de violencia.

Si esto ha sido posible en las narraciones de las mujeres y sus padecimientos, seguramente se debió a lo que definió Celia Amorós (1985) como, “el espacio de las idénticas”, lugar que el orden cultural reservó a las mujeres como grupo indiscriminado. La noción de "las idénticas” aludiría a un contrato social en el cual las mismas son seres intercambiables tanto entre unas y otras, como dentro de la diferencia generacional (la cursiva es mía).

De acuerdo con Celia Amorós, la violencia simbólica es producto de una red de pactos tejida entre varones, que los constituye como iguales, o como diferentes en la semejanza, mediante el Logos que les autoriza a hablar y a ser escuchados. Este pacto entre varones, que ella llama "fratría", excluye todo aquello que sea Otro, todo lo femenino, quedando las mujeres confinadas al "espacio de las idénticas” donde, según sus palabras, no existe nada que repartir ni pactar, pues se es objeto de reparto y pacto 
por parte de los hombres. Si la pertenencia a este lugar, el de las idénticas, ubica a las mujeres en un espacio desde el cual la palabra no es una palabra autorizada, no debe llamar la atención que los relatos de las mujeres abusadas hayan sido históricamente desmentidos, acontecimiento similar a lo acontecido con los relatos de las víctimas de terrorismo de Estado. Los colectivos subordinados no pertenecen al Logos autorizado y validado cuando lo que develan es la práctica de violencia.

El incesto se constituye como el representante máximo del proceso de cosificación del otro, en un accionar signado por la destrucción devastadora no solamente en el cuerpo sino también (y este daño no es menor) a la cadena de filiación que sostiene a los sujetos dentro de un orden cultural.

La gravedad del incesto abre interrogantes en lo que se refiere al padecimiento individual de un sujeto sometido a este tipo de violencias y también al efecto psíquico y simbólico de la violencia de la desmentida social, que viene siendo obstáculo para la elaboración de la experiencia traumática y que de alguna manera, al negarla, la habilita.

El asalto sexual de un padre hacia una niña rompe definitivamente con dos leyes estructuradoras de nuestra cultura, que se condensan en la narrativa edípica: la prohibición del incesto, con su consecuente aseguramiento de la salida de la endogamia para pasar a la exogamia, y la conservación de la diferencia generacional en función del sostén afectivo deseante que constituye a un sujeto. Lo que el padre interdicta en el niño tiene que estar prohibido por carácter reflejo a sí mismo, dato no menor cuando se analiza la incidencia de la interdicción en la conflictiva edípica. Podríamos decir que no es solamente "no con tu madre sino con otras", sino y anterior a esto, " $n i$ tu padre ni tu madre contigo".

Nosotros todos estamos constituidos por la Ley de prohibición del Incesto fundante de la cultura que es lo que nos permite advenir sujetos. El abuso sexual pone fin a la constancia de esta ley en nuestro psiquismo, con la consecuente catástrofe psíquica que acarrea ser un sujeto atravesado por una práctica que nos pone afuera de la misma y adquirir en algún lugar el status de lo que denomina Judith Butler (Butler, 2000) “cuerpos abyectos”, denominación que la autora utiliza para designar a los sujetos 
que se constituyen por fuera del orden falologocéntrico que divide a los seres humanos en dos géneros complementarios.

En este caso utilizaré el término de abyección para denominar la vivencia que presentan la mujeres que han sobrevivido a un ataque incestuoso ${ }^{7}$ tomando como aspecto primordial el efecto que tiene a lo largo del tiempo el haber sido obligadas a transgredir una ley constitutiva de la sociabilidad en los seres humanos. Esta ley ${ }^{8}$ no solamente asegura la salida exogámica sino que legisla sobre la necesidad del sostén afectivo no genitalizado por parte de las figuras significativas, de esta manera lo que se interdicta habilitaría la circulación de fantasías edípicas que aseguren en su juego fantasmático la salida hacia otros por fuera del grupo familiar.

El uso del término abyección definirá la marca residual traumática de la violencia ejercida al cuerpo y al psiquismo de la niña por un padre que la coloca con su accionar por fuera del orden cultural reinante, al que fuera introducida desde el momento de su concepción.

La irrupción del incesto en la vida de una niña, rompe con la cadena de filiación y de cuidado que marcan las formas de subjetivar dentro del orden cultural, de la cual participamos todos. El padre perverso adquiere por este accionar el status de representante de la ley en sí mismo, se erige en padre de la horda, sometiendo a sus hijos al imperio de su violencia sabiendo que esta situación tiene que mantenerse en secreto porque desafía la ley de la cultura y por lo tanto él en su accionar transgrede lo que de alguna manera también acata.

Si el Complejo de Edipo y su atravesamiento instala a un sujeto dentro de un orden cultural en el que transitamos todos, las mujeres que han padecido ataques incestuosos, han sido obligadas a transgredir esta estructura fundamental.

\footnotetext{
${ }^{7}$ Judith Butler hace especial hincapié en que la noción de abyección alude a la noción de lo abyecto como lo que no puede entrar dentro del campo de lo social sin amenazar de alguna manera la disolución del sujeto por tener que incorporar lo escindido que de llevarlo a cabo lo psicotizaría.

${ }^{8}$ La prohibición del incesto no es una ley natural sino que marca una construcción social que habilitaría al sujeto advenir a la cultura.
} 
Es muy frecuente que mujeres que han sido abusadas de niñas relaten la sensación de ser “distintas” a partir del episodio del abuso con respecto a las demás niñas, estas verbalizaciones representarían la doble vida a las que son sometidas. Por un lado una cara pública dentro de un orden cultural edípico, y por otro lado la vida oculta dentro de un orden cultural individual y secreto que depende del "padre de la horda” y su violencia.

Lo traumático del asalto incestuoso tiene como efecto no solamente el daño físico que la acción violenta supone, sino también a nivel subjetivo y simbólico, la ruptura de la figura del padre como genitor, y asegurador del bienestar psicofísico de la niña (Giberti, 2000). Lo no representable en la experiencia de abuso incestuoso estaría referido entonces a la aparición disruptiva en la figura del padre de un accionar que contiene un acto perverso, dándole a este actuar un contenido erótico que no es más que la puesta en acto del odio en clave de erotización (Stoller, 2000).

Si el deseo está en relación con la carencia, en el incesto se rompe definitivamente con el juego deseante. El vínculo que instala el padre incestuoso tiene características genitales, traumáticas, e intrusivas, desestructurando el funcionamiento deseante de la hija, cosificándola en relación a su propio deseo, produciendo la deposición de la estructuración defensiva por arrasamiento, generando una catástrofe psíquica no solo a nivel afectivo sino en relación a funcionamiento del esquema de pensamiento.

El juego de ausencias y presencias (Green, 2001) del objeto es necesario para producir deseo y por lo tanto instaurar la función deseante edípica, en el incesto lo real taponaría el deseo. Desencadena lo que Andre Green denomina "angustia de intrusión” y que tiene que ver con la posibilidad de que el objeto significativo exceda en su accionar cierto grado de umbral con lo que provoca reacciones catastróficas con experiencias de desintegración (Green, 2001) produciendo no solamente problemática a nivel del funcionamiento deseante, sino también a nivel del funcionamiento del pensamiento (Bión, citado por Green). Es llamativo que el autor denomina a este tipo de angustia como típica de la sexualidad femenina sin poder interrogarse que relación hay 
entre la histórica posición de objeto de la mujer, la vivencia de ser pasible de violencia y la angustia de intromisión.

En lo que se refiere a la construcción del pensamiento es necesario constituir una ausencia para que haya espacio psíquico para fantasear,

el objeto siempre presente de manera intrusiva moviliza una contrainvestidura para poder luchar con esa invasión que agota los recursos yoicos como forma de desembarazarse del objeto. Tanto la presencia invasora que produce el sentimiento delirante de influencia, como la inaccesibilidad que produce depresión, traen consecuencias profundas para la construcción del pensamiento porque en los dos es importante constituir la ausencia. El objeto siempre presente que penetra en permanencia en el pensamiento moviliza una contrainvestidura permanente para luchar contra ésta. Se agotan los recursos del yo. El objeto nunca está ausente y por lo tanto no puede ser pensado. El objeto inaccesible nunca puede ser traído al espacio del pensamiento o no se queda de manera duradera, por eso no puede ser significado de manera duradera (Green, 2001).

El cuerpo de la niña en el accionar incestuoso está siendo utilizado para procesar angustias de modalidad perversa por parte del adulto, ya que el odio está vehiculizado en clave de erotización (Stoller, 2000). Al producirse el acto en lo real lo que no se permite es la circulación del deseo por ausencia de objeto, que habilitaría tanto el fantaseo como la búsqueda de otros por fuera de la estructura primigenia. Por lo anteriormente expuesto es por lo que ya en otros trabajos denominé a este tipo de accionar sobre las mujeres “una perversión de género” (Fridman, 2004) en la cual la acción que se produce tiene que ver con la concreción del odio a la diferencia vehiculizado en clave de erotismo (como lo denomina Robert Stoller "la erotización del odio”) y llevado a cabo en el cuerpo de las mujeres. Acción en la cual se conjuga la necesidad del miedo del otro, el control omnipotente, el goce que produce este tipo de accionar y el daño consecuente, unidos en la capacidad de gozar del que lleva a cabo la 
acción. Es lo que Lacan denominó en el escrito Kant con Sade "la felicidad en el mal” jugado en el cuerpo de las mujeres ${ }^{9}$.

La dificultad en la posibilidad de narrar lo traumático del incesto tiene que ver con la aparición en las mujeres de sentimientos de “vergüenza” y “la culpa”. Afectos que según Bruno Bettelheim, un psicoanalista que en su juventud fue internado en un campo de concentración nazi, marcó como típicos de muchos de los sobrevivientes de campos de concentración. Dice el autor que la culpa y la vergüenza "nos hace humanos, sobre todo si objetivamente no somos culpables”. La culpa nos coloca en el lugar de sujetos en el entramado de la cultura más allá de lo que se denomina la "nuda vida”.

Giorgio Agamben en relación a los sobrevivientes de campo de concentración toma la noción de vergüenza en un doble sentido: según él la vergüenza se experimenta en el momento en que un accionar sobre un sujeto lo obliga a adoptar una posición de desubjetivación pero en ese instante que se negocia esa posición como modo de sostener su vida, ese individuo está siendo sujeto. Dice Agamben (2000) (la cursiva es mía):

La vergüenza es nada menos que el sentimiento fundamental de ser sujeto en los dos sentidos opuestos -al menos en apariencia- de este término: estar sometido y ser soberano. Es lo que se produce en la absoluta concomitancia entre una subjetivación y una desubjetivación, entre un perderse y poseerse entre una servidumbre y una soberanía (...). Aquí la analogía con la vergüenza que hemos definido como el ser entregados a una pasividad inasumible sale a la luz, y la vergüenza se presenta incluso como la tonalidad emotiva más propicia de la subjetividad.

La ética post Auschwitz nos demanda escuchar para reelaborar lo no dicho, lo desmentido, lo siniestro y parte de lo siniestro es lo que De Press desarrolla en un postulado que se podría sintetizar de la siguiente manera: el superviviente elige la vida, y para eso tiene que aceptar someterse a lo indecible.

\footnotetext{
${ }^{9}$ Boris Cyrulnik menciona que Sade pensaba que esta forma de interdicción era una forma de opresión social que no se justificaba, en parte depositando los deseos de consumación de incesto en las víctimas igualando este deseo con el del perpetrador.
} 
Una paciente que había sido abusada en su infancia me relataba después de años de elaboración de esta situación que ella sabía conscientemente que si no se sometía, su padre no la dejaba salir ni hacer nada, sino que tenía un nuevo arranque de violencia; ella vivía con mucha culpa y vergüenza este proceder, “este sometimiento” no pudiendo aceptar la idea de que la desubjetivación a la que era sometida tenía lugar como negociación entre la vida y la muerte; el trabajo con ella fue la aceptación de que para vivir ella había tenido que hacer negociaciones. Como dice una sobreviviente de Auschwitz: "Ningún hombre tendría que haber sido obligado a pasar por lo que pasó”. Es lo que ya denominé en otro trabajo "la vergüenza de dejarse hacer”(Fridman, 2005).

Históricamente las mujeres hemos sido cuerpo sin palabra, cuerpo para parir, cuerpo para criar y cuerpo depositario de violencia, por lo tanto objeto del deseo del otro, cualquiera sea el deseo que se trate, inclusive el deseo de daño. Es por esto que insistimos en la gravedad que ha tenido históricamente la desmentida que ha realizado cierta conceptualización psicoanalítica al confundir fantasía con suceso traumático real. La presencia de sintomatologías graves tanto a nivel de funcionamiento de las operaciones del pensamiento como a nivel corporal nos hablan de las gravísimas consecuencias que estos sucesos padecidos en la infancia genera en las sobrevivientes de incesto. La presencia de fobias graves, dificultades en el contacto intersubjetivo, en algunos casos anorexias o bulimias, problemáticas a nivel de la integración corporal, anestesias corporales, intentos de suicidios, conductas promiscuas, dificultad de poner en palabras lo que perciben, la duda permanente cuando enfrentan un conflicto acerca de si lo que están viviendo es verdad o no y los efectos de desmentida que se producen cuando atraviesan algún acontecimiento traumático hablan de la gravedad del trauma padecido en la infancia.

El trabajo terapéutico apunta a poder reelaborar los aspectos de lo siniestro sin palabras, allí donde se operó la desmantelación subjetiva, y también significa poder aceptar la convivencia de la posibilidad de elaboración, con lo penoso de la permanencia del trauma, lo que Primo Levi denominó el “siempre presente”. 


\section{Bibliografía}

Agamben, Giorgio (2000): Lo que queda de Auschwitz. Valencia, Pretextos.

Amorós, Celia (1991): Hacia una crítica de la razón patriarcal. Madrid, Ánthropos.

Bleichmar, Emilce Dio (1991): El feminismo espontáneo de la histeria. Madrid, Siglo XXI.

-(1998) La sexualidad femenina. Madrid, Paidós.

Braidotti, Rossi (2000): Sujetos nomades, Buenos Aires, Paidós.

Bourdie, Pierre (1999): Intelectuales,politica y poder. Buenos Aires, Ed. EUDEBA

Butler, Judith (2002): Cuerpos que importan. Buenos Aires, Paidós.

Edelman, Lucila, Kordon, Diana, Lagos Darío (1995): La impunidad. Una perspectiva psicosocial y clínica. Buenos Aires, Ed. Sudamericana.

Fernández, Ana María (1993): La mujer de la ilusión. Buenos Aires, Paidós.

Freud, Sigmund (1973): Obras Completas. Madrid, Ed. Biblioteca Nueva. [Incluyen Tótem y Tabú (1912-13), Introducción al narcisismo (1914), Lo siniestro (1919)].

Fridman, Irene (2000): “La búsqueda del padre. El dilema de la masculinidad”, en I. Meler y D. Tajer. Psicoanálisis y Género, Buenos Aires, Lugar, pp. 283-298.

- (2000): “El lado oscuro de la paternidad”, en Ana María Daskal (comp.). El malestar en la diversidad. Chile, Isis Internacional, pp. 57-66.

-(2005): “Elaborando lo siniestro: Violación e Incesto su efecto en los equipos de atención”, en Delitos contra la integridad sexual. Documento 3. Gobierno de la ciudad de Buenos Aires, pp. 50-55.

-(2005): “Lo siniestro de la cultura. Trabajando con violencia sexual”, en Chester, Larcamon y Ruffa (eds.): Aportes para la intervención en el Sistema Público, pp. 36-43.

Giberti, Eva (1996): Incesto paterno-filial. Buenos Aires, Editorial Universidad.

Green, A. (1995): Narcisismo de vida, narcisismo de muerte. Buenos Aires, Amorrortu.

Hornstein, Luis (2000): Narcisismo, Autoestima, identidad, alteridad. Buenos Aires, Paidós.

Israel, Lucien (1979): El goce de la histérica. Barcelona, Argonauta. 
Poner en palabras lo traumático: Mujeres sobrevivientes de abuso sexual

Kuitca María Lea K. (2000): Violencia familiar y abuso sexual infanto-juvenil. Rev. Psicoanálisis APdeBA - Vol. XXII - No 2.

La Capra, Dominick (2005): Escribir la historia, escribir el trauma. Buenos Aires, Ed. Nueva Visón.

Lewcowic, Ignacio (2002): “Conferencia”, en Clínica Psicoanalítica ante las catástrofes sociales, Buenos Aires.

Luna Florencia, Arleen Salles (1995): Decisiones de vida o muerte. Buenos Aires, Ed. Sudamericana.

Masson, Jeffrey (1985): El asalto a la verdad. Barcelona, Seix Barral.

Memmi, Albert (1997): The Colonizador and the colonizad. Boston, Bacon Press.

Rogers, Annie (2000): “Voces exiliadas. La disociación y el retorno de lo reprimido en los relatos de mujeres”, en Ana Maria Daskal (comp.): El malestar en la diversidad. Chile. Isis, № 29, pp. 33-56.

Ricoeur, Paul (2004): La Memoria, la historia y el olvido. Buenos Aires, Fondo de Cultura Económica.

Stern, Lori (1991): “Disavowing the self infamales adolescence”, en Gilligan, Rogers y Tolman (eds.): Reframing Resistence: Women, Girls and Psychoterapy. New York, Harrington Park Press.

Stoller, Robert (1993): Dolor y passion. Argentina, Ed. Manantial.

Tessone, Juan José (2004): Los incestos y la alteridad (Conferencia dictada en APdeBA 11 de mayo 2004, Buenos Aires). 